\title{
Minería, mano de obra, y circulación monetaria en los Andes colombianos del siglo XVII
}

\author{
Heraclio Bonilla \\ Universidad Nacional de Colombia
}

\begin{abstract}
Resumen
La economía en el Nuevo Reino de Granada giró casi exclusivamente en torno al oro de aluvión. Pese a esa situación, el examen del sector minero de la plata permite, analizar con mayor precisión los grandes temas que han preocupado a la historiografía colonial, y cuyos resultados se espera contribuyan tanto a contextualizar mejor la historia de la minería americana durante el periodo colonial como a un mayor conocimiento de la economía animada por la plata en la Nueva Granada. Este artículo, que hace parte de una investigación en curso, trata, en este orden, sobre los espacios de la plata, la articulación entre extracción y circulación monetaria, y el papel de la mano de obra como determinante de esos ciclos.
\end{abstract}

\begin{abstract}
La economía en el Nuevo Reino de Granada giró casi exclusivamente en torno al oro de aluvión. Pese a esa situación, el examen del sector minero de la plata permite, analizar con mayor precisión los grandes temas que han preocupado a la historiografía colonial, y cuyos resultados se espera contribuyan tanto a contextualizar mejor la historia de la minería americana durante el periodo colonial como a un mayor conocimiento de la economía animada por la plata en la Nueva Granada. Este artículo, que hace parte de una investigación en curso, trata, en este orden, sobre los espacios de la plata, la articulación entre extracción y circulación monetaria, y el papel de la mano de obra como determinante de esos ciclos.
\end{abstract}

Ponencia presentada en la VII Reunión de Historiadores de la Minería Latinoamericana, Universidad Arturo Prat, Iquique, 1 al 4 de agosto de 2001. Agradezco a Vladimir Cristancho y a Constanza Reyes, del Departamento de Historia de la Universidad Nacional de Colombia, su ayuda en la preparación del gráfico de las emisiones monetarias de la ceca de Santafé. 
"En un debate parlamentario sobre las leyes bancarias de Sir Robert Peel de 1844 y 1845, Gladstone observó que ni siquiera el amor había hecho perder la cabeza a tanta gente como el cavilar acerca de la naturaleza del dinero. Hablaba de inglés a inglés."1

En una síntesis reciente sobre la historia económica colonial Anthony McFarlane constataba “... [que] debemos cuidarnos desde el principio de no exagerar la riqueza que el oro producía. Pues en términos de escala, organización y tecnología, así como en el dinamismo económico que generaba, la minería de oro en la Nueva Granada no es para nada comparable con las grandes industrias de la plata en el México o en el Perú contemporáneos, o con los yacimientos auríferos del Brasil del siglo XVIII."2 Esa marginalidad es mucho más acentuada en el caso de la plata, puesto que la economía minera del Nuevo Reino giró casi exclusivamente en torno al oro extraído en el siglo XVIII fundamentalmente por una mano de obra esclava. Pese a esa situación, o tal vez por eso, el examen del sector minero de la plata permite, por su localización, examinar con mayor precisión los grandes temas que han preocupado a la historiografía colonial, y cuyos resultados se espera contribuyan tanto a contextualizar mejor la historia de la minería americana durante el período colonial como a un mayor conocimiento de la economía animada por la plata en la Nueva Granada. Las páginas que siguen son un adelanto de una investigación en curso y tratan, en este orden, sobre los espacios de la plata, la articulación entre extracción y circulación monetaria, y el papel de la mano de obra como determinante de esos ciclos.

\section{Los espacios mineros}

En un espacio caracterizado por el oro de aluviones o de vetas, las escasas áreas con plata se encontraron en Mariquita e Ibagué, al oriente del Batolito del Tolima según el recuento clásico de West, ${ }^{3}$ y cuya explotación se inició con la fundación de San Sebastián de Mariquita en 1551. Otra zona importante fue San Sebastián de la Plata, en la vertiente oriental de la cordillera, pero cuyo desarrollo fue afectado por el ataque de

\footnotetext{
${ }^{1}$ Karl Marx, Contribución a la crítica de la economía política (Moscú: Progreso, 1989), 51.

2 Anthony McFarlane, Colombia antes de la Independencia: Economía, sociedad y política bajo el dominio borbón (Bogotá: Banco de la República, 1997), 117-8.

${ }^{3}$ Robert West, La minería de aluvión en Colombia durante el periodo colonial (Bogotá: Imprenta Nacional, 1972), 42.
} 
los indios. Además, otro centro minero trabajado parcialmente con indios de mita fue el de Pamplona. De ellos, los más importantes fueron ciertamente los de Mariquita cuyos filones produjeron por fundición cuatro marcos por quintal. ${ }^{4}$ Antonio González, presidente del Nuevo Reino, en su informe de 1590 señala que en Mariquita había cinco ingenios con una capacidad individual de molienda de catorce a quince mil quintales de metal por año, ${ }^{5}$ a un promedio de cincuenta quintales diarios y con un rendimiento de cinco onzas por cada uno, es decir 7,812 marcos y medio por ingenio. Su producción cesó abruptamente en 1720 al prohibir el Rey que "ningún indio se le obligue a la labor de minas," a la falta de destreza de los mineros", y a los altos costos del azogue introducidos desde España o el Perú y cuyos precios en el siglo XVII eran de ciento diez pesos dos reales por quintal en Bogotá y Mariquita y trescientos pesos en Popayán. ${ }^{8}$ Según la visita realizada en 1640 por Gonzalo de Murillo Velarde y Antonio González existían en ese año en Santa Ana nueve minas en explotación, las que ocupaban 210 indios, 189 negros y 40 negras, y ocho ingenios de amalgamación con 81 indios, 76 negros y 3 negras "fuera de operarios de chusma," mientras que Las Lajas contaba con diez minas de laboreo, en las que trabajaban 207 indios y 9 negros y seis ingenios con 63 indios. ${ }^{9}$ Sobre las condiciones de trabajo de los indios en Mariquita, y sobre sus consecuencias para el conjunto de la economía colonial el Presidente de la Audiencia D. Antonio Manso reflexionaba en 1729 en los términos siguientes:

Hecha la conducción, lo que sucede es que salen los indios de unos temples frigidísimos a las minas de Mariquita, que son calidísimas: trabajan dentro del agua con el peso de una barra, a que no están acostumbrados, con que dentro de poco enferman si no mueren muchos a pocos días que experimentan el trabajo, se huyen y se aplican a bogar en las canoas del trajín que hay en el río de la Magdalena, o se alejan más distantes, con que es raro que vuelvan a su pueblo. Lo peor es que en seguimiento del marido se suelen ir la mujer e hijos pequeños con él a las minas, y perdido él ninguno de los que salieron vuelve, y si alguno vuelve es inútil ya del todo, porque o viene azogado o medio tullido y perdida la salud para siempre. Sucede también que siendo obligados los Capitanes a pagar

\footnotetext{
${ }^{4}$ José V. Restrepo, Estudio sobre las minas de oro y plata de Colombia (Bogotá: Banco de la República, 1952), 123.

${ }^{5}$ Ibid., 124.

${ }^{6}$ Ibid., 219.

7 "En cuanto a inteligencia en los mineros para vencer dificultades, no ha habido alguno que lo haya sabido hacer. A los beneficiadores azogueros se les perdía mucha plata por falta de ciencia, de tal modo que daban las cuentas que ellos querían, sin que esto hubiera reparo ni medio". Ibid., 221.

${ }^{8}$ Ibid., 222.

${ }^{9}$ Ibid., 129.
} 
la demora de los ausentes, tienen que salir de su pueblo a buscarlos, en que consumen meses enteros; y si no los hallan acontece también el no volver, con que se destruyen en cada conducción enteramente los pueblos, minorándose los tributos, y va faltando cada día este renglón a la real hacienda. Falta quien cultive los campos y quien acarree los mantenimientos, con que dentro de poco faltará todo. Este horrible inconveniente es mayor de lo que se puede ponderar. ${ }^{10}$

\section{Producción y circulación monetaria}

Desde la publicación en 1934 del ya clásico libro de Earl J. Hamilton sobre el impacto de la exportación de los metales preciosos en la economía española del Siglo de Oro, ${ }^{11}$ investigadores como David Brading, Harry Cross ${ }^{12}$ y Peter J. Bakewell ${ }^{13}$ han continuado sus esfuerzos por cuantificar la extracción y la exportación de los mismos. Para la Nueva Granada una tarea similar fue asumida por Germán Colmenares, ${ }^{14}$ Zamira Díaz ${ }^{15}$ y Jorge Orlando Melo, ${ }^{16}$ aunque los resultados están lejos de ser concluyentes. Y en el caso de la plata, dada su marginalidad ya señalada, la situación es aún más crítica: no existe ninguna serie continua ni para la producción ni para las exportaciones. Por consiguiente, la única manera de saber algo sobre su desempeño es analizar las emisiones monetarias en plata de las Casas de Moneda, particularmente la de Santafé que fuera fundada en 1620 y la única dedicada a la labranza de la plata de Mariquita hasta el agotamiento de sus yacimientos. En cambio, la de Popayán, fundada en 1726 pero con actividad normal sólo después de 1758, acuñó la plata obtenida en el tratamiento del oro y para un período en el cual la extracción de Mariquita había virtualmente cesado.

\footnotetext{
${ }^{10}$ Ibid., 219.

${ }^{11}$ Earl J. Hamilton, El tesoro americano y la revolución de los precios en España, 1501-1650 (Barcelona: Ariel, 1975).

12 David A. Brading y Harry E. Cross, "Colonial Silver Mining: Mexico and Peru," Hispanic American Historical Review 52, no. 4 (1972).

${ }^{13}$ Peter J. Bakewell, Silver Mining and Society in Colonial Mexico: Zacatecas, 1546-1700 (Cambridge: Cambridge University Press, 1971).

${ }^{14}$ Germán Colmenares, Historia económica y social de Colombia I, 1537-1719 (Bogotá: Tercer Mundo, 1997).

${ }^{15}$ Zamira Díaz L., Oro, sociedad y economía: El sistema colonial en la Gobernación de Popayán, $1533-$ 1733 (Bogotá: Banco de la República, 1994).

${ }^{16}$ Jorge O. Melo, "Producción de oro y desarrollo económico en el siglo XVIII," en Sobre historia y política, Colección La Carreta (Medellín: Lealon, 1979), 61-84.
} 
Las cifras de la acuñación de plata en la ceca de Santafé han sido tomadas del trabajo de Guillermo Céspedes del Castillo, ${ }^{17}$ quien a su vez se basa en las estadísticas (discutibles) de Vicente Restrepo ${ }^{18}$ y A.M. Barriga. ${ }^{19}$ Han sido convertidos sus valores en maravedíes, a razón de 272 maravedíes por peso, a fin de permitir un primer contraste con las cifras discontinuas de producción de plata en Mariquita elaborada por Julián Ruiz en su trabajo pionero, ${ }^{20}$ y que fueron calculadas a partir del pago de los impuestos pagados por los mineros de Las Lajas (el principal centro minero de esa región) a la Corona. En contraste con Potosí los mineros no pagaron el conocido quinto, y ni siquiera el diezmo (que fue pagado solo entre 1590 y 1597) sino sólo el veinteno, es decir el veinteavo del valor de la producción. ${ }^{21}$

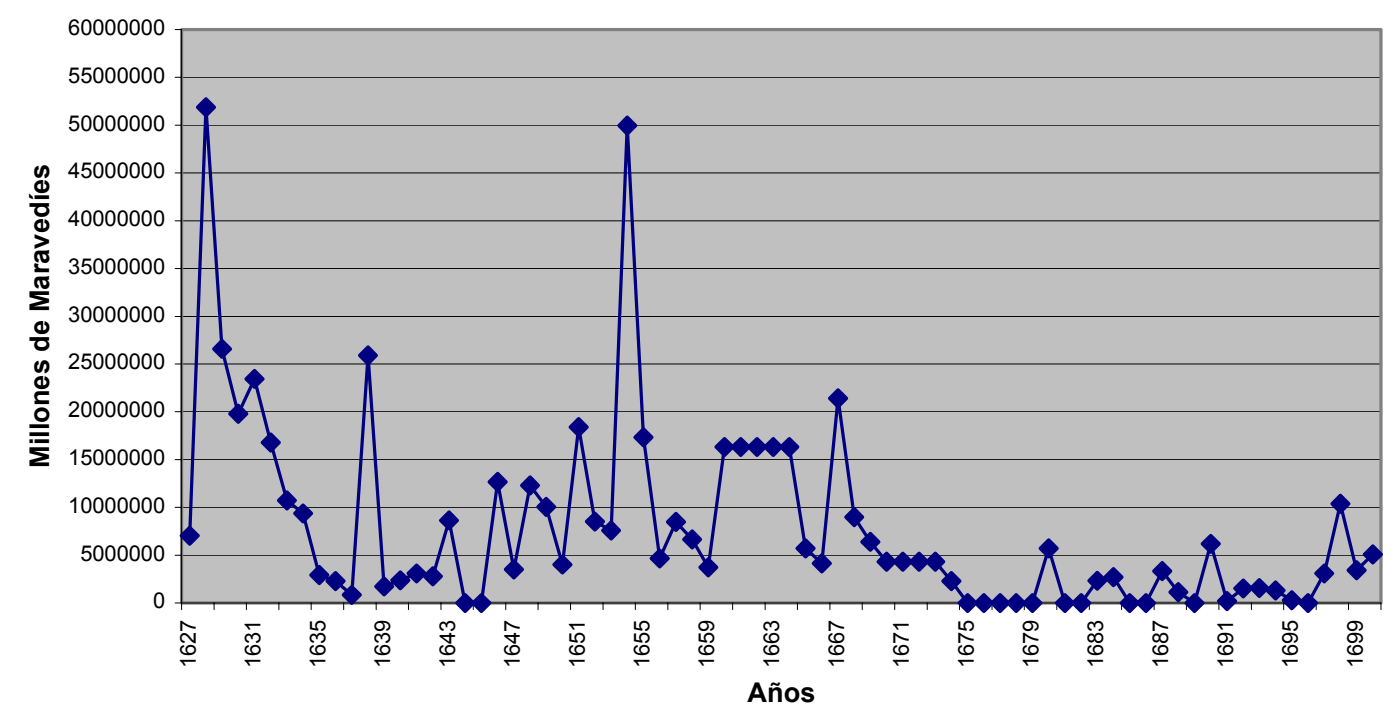

Fig. 1. Acunación de plata de la casa de la moneda de Santafé 1627-1700. (Fuente: Céspedes del Castillo, Las cecas indianas, 262-8.)

\footnotetext{
${ }^{17}$ Guillermo Céspedes del Castillo, Las cecas indianas en 1536-1825, vol. 1 de Las casas de moneda en los reinos de Indias (Madrid: Museo Casa de la Moneda, 1996), 262-8.

${ }^{18}$ Restrepo, Estudio sobre las minas.

${ }^{19}$ Antonio M. Barriga Villalba, Historia de la casa de moneda, 3 vols. (Bogotá: Banco de la República, 1969).

${ }^{20}$ Julián B. Ruiz Rivera, La plata de Mariquita en el siglo XVII: Mita y producción, Cuadernos de historia, no. 5 (Tunja: Nuestra América, 1979).

${ }^{21}$ Ibid., 20.
} 


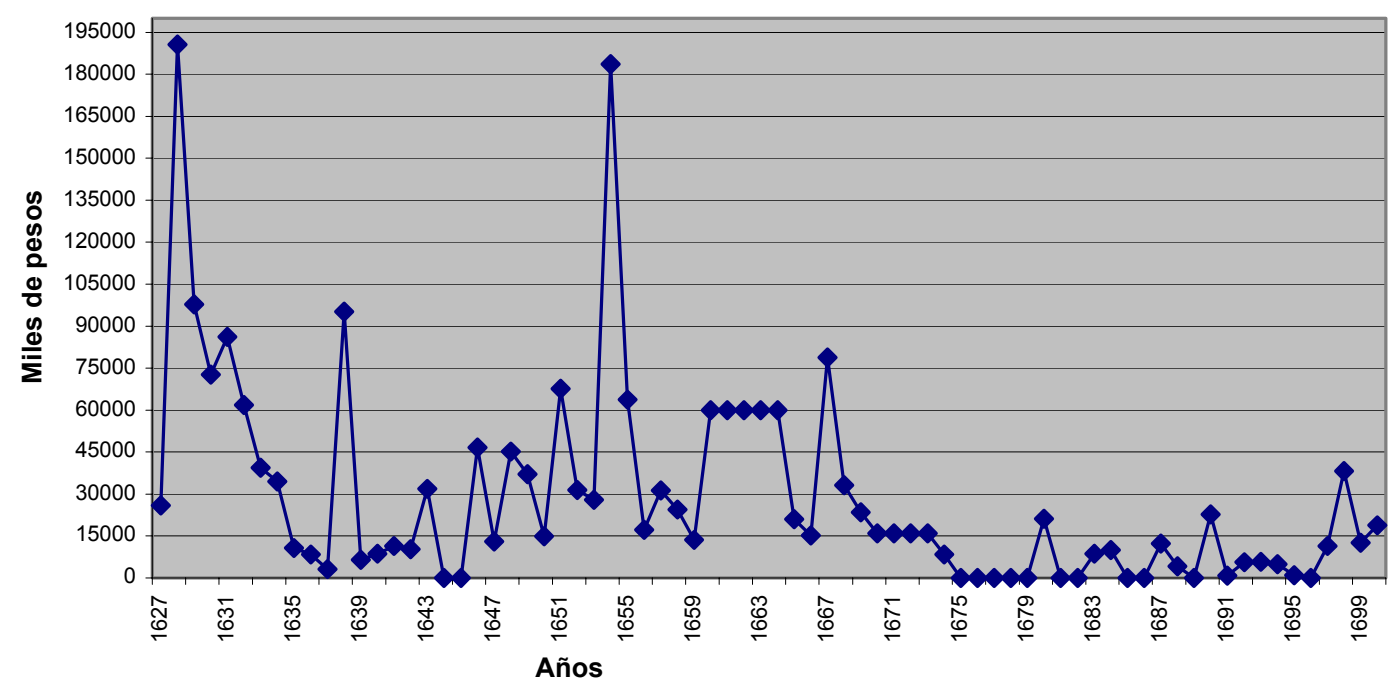

Fig. 2. Acuñación de plata en la casa de la moneda de Santafé 1627-1700. (Fuente: Guillermo Céspedes del Castillo, Las cecas indianas, 262-8.)

El gráfico de la acuñación de plata en Santafé muestra, con altibajos obvios, tres tendencias muy claras: la primera, de repunte y caída, entre los años de 1627 a 1637; la segunda, de expansión y que cubre el período entre 1638 y 1654 ; la tercera, de declive desde 1655 hasta fines del siglo, con un intervalo de recuperación en el decenio de 1657 a 1667. En términos de la producción, el gráfico elaborado por Ruiz y que se reproduce en el anexo, señala un primer ciclo con una producción muy débil y estancada y que se extiende hasta 1615; un segundo que comprende los años entre 1620 y 1633, caracterizado por un crecimiento notable; un tercero, que se prolonga hasta 1658 y que es de contracción; un cuarto, que se inicia con una expansión importante en los años 1659 y 1660, para continuar con un declive hasta el ocaso de finales del XVII, aunque los años entre 1670 y 1683 , representaron una excepción en esta tendencia declinante. 


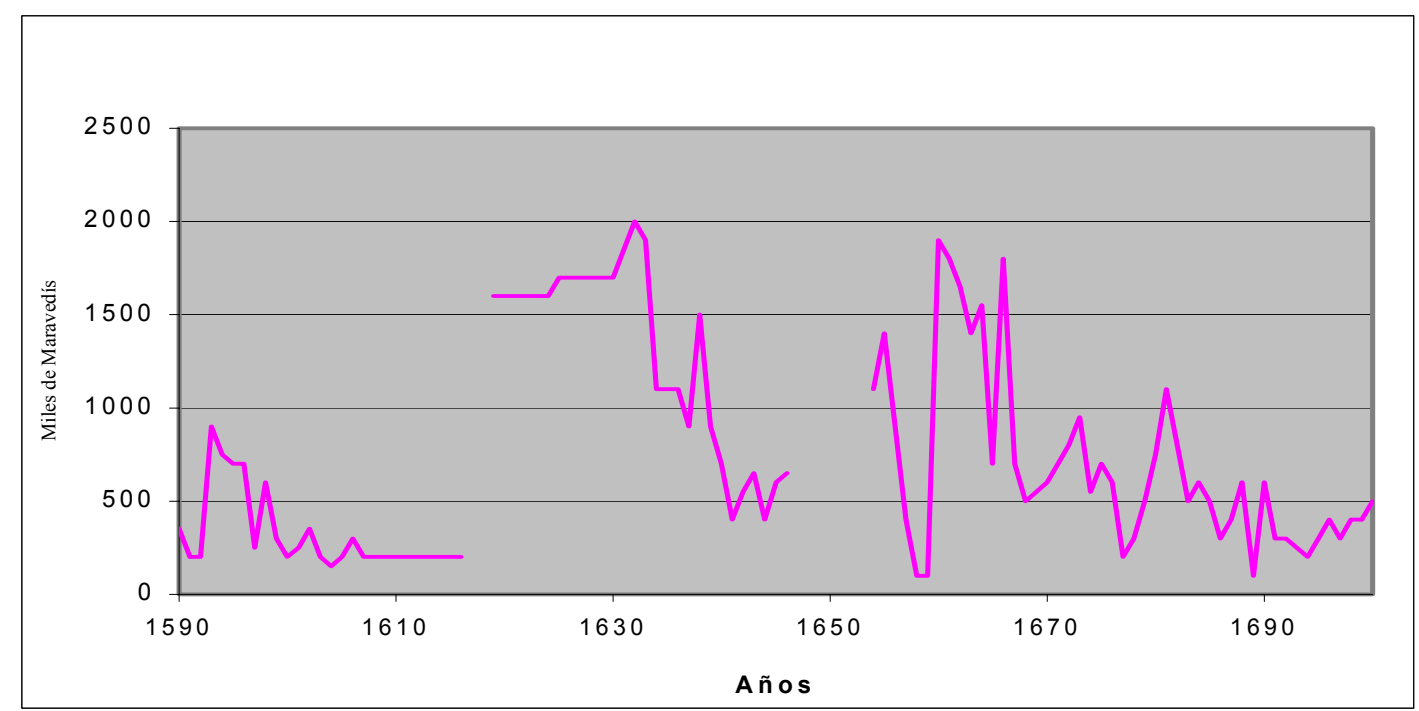

Fig. 3. Derechos de plata de las Minas de Las Lajas y sus ciclos, 1590-1701. (Fuente: Ruiz, La plata de Mariquita, 23-4.)

La comparación entre los ciclos de la emisión monetaria de la ceca de Santafé como los de la extracción de la plata de la región de Mariquita permite formular una primera constatación y dos interrogantes. La constatación es muy simple y abre una serie de preguntas que deben guiar indagaciones futuras. Ocurre en efecto, que el valor de las emisiones monetarias parecen muy cercanas al valor de la producción de las minas de Las Lajas en los cálculos realizados por Julián Ruiz. Parecen, porque desafortunadamente no se cuenta con las cifras que corresponden a los gráficos, como tampoco la base de la conversión en maravedís. Este es un problema central que la investigación futura debiera resolver. En el supuesto de que la reconstrucción de ambas cifras sea razonablemente rigurosa, cabe la posibilidad de que el conjunto de esa producción fuese encaminada a la ceca de Santafé para su acuñación, sospecha poco razonable por lo que se sabe del comercio ilegal, pero en el caso de que productores y comerciantes hayan sido respetuosos de la ley, ¿qué ocurrió entonces con la producción de plata de los otros yacimientos de plata? En un trabajo reciente Hermes Tovar ${ }^{22}$

\footnotetext{
${ }^{22}$ Hermes Tovar Pinzón, "Remesas: situados y Real Hacienda en el siglo XVII,” en Dinero, moneda y crédito en la monarquía hispánica, ed. Antonio M. Bernal, Ediciones de historia (Madrid: Marcial Pons, 2000), 241-67.
} 
afirma, refiriéndose al oro y para el conjunto de la economía de la Nueva Granada del siglo XVII:

Cartagena de Indias, que era la llave por donde fluía el metal del interior del Reino, recibió entre 1600 y 1699 unos 2,291,972,073 maravedís, o sea, unos 6,111,926 ducados con el fin de ser remesados a España. De esa cifra sólo se remitieron 1,246,964,827 maravedís, es decir el 54.4 por ciento de lo recibido. Es decir, que el 45.6 por ciento de las rentas netas que produjo el Nuevo Reino se redistribuyó en las colonias con necesidades de diferente género. ${ }^{23}$

Pero las monedas de plata acuñadas por la ceca de Santafé plantean igualmente un primer interrogante en torno al significado de la dimensión monetaria en un contexto colonial. Cabe recordar, a este respecto, que la economía del Nuevo Reino, en contraste con la de Nueva España y el Perú, era fundamentalmente de oro, metal cuya circulación en barras o en grano fue frontalmente prohibida por la Corona. Por lo mismo, la escasez de la plata constituyó una barrera muy seria a sus deseos de imponer como monedas el peso de ocho reales y el vellón, contexto en el cual el surgimiento de las minas de plata de Mariquita representaba un importante alivio. Pese a que la necesidad de contar con una unidad monetaria confiable era percibida tanto por las autoridades reales como por los diversos agentes económicos, sin embargo los desacuerdos sobre el tipo de moneda llevaron al fracaso de la experiencia asumida por la oficina de Cartagena de acuñar una moneda provincial de baja ley en reemplazo de la plata corriente que circulaba sin acuñar en su entorno. En 1626, cuando se habían troquelado monedas por un valor de 5,409 pesos, la emisión fue retirada y sustituida por monedas de plata de ley. ${ }^{24}$

Las emisiones de la ceca de Santafé, por mínimas que éstas hayan sido con relación al volumen de plata producido en Mariquita, plantean otros problemas y que en parte se relacionan al debate sobre el papel de la moneda en el conjunto de la economía colonial. Como se sabe, en el contexto de la Nueva España y del Perú las posiciones opuestas las representan las propuestas de Ruggiero Romano y de Carlos Sempat Assadourian, subrayando el último el papel central de la circulación de la plata en la mercantilización de la economía, mientras que Romano sostiene el papel dominante del sector natural. Los argumentos de su tesis, agrupados en un importante libro reciente, ${ }^{25}$ aluden a la

\footnotetext{
${ }^{23}$ Ibid, 264.

${ }^{24}$ Céspedes del Castillo, Las cecas indianas, 262.

${ }^{25}$ Ruggiero Romano, Monedas, seudomonedas y circulación monetaria en las economías de México (México, D.F.: Fondo de Cultura Económica, 1999)
} 
sangría de la plata, es decir en el caso de México a su éxodo por Acapulco y por Veracruz, y a la naturaleza aristocrática de estas emisiones monetarias, o sea que fueron utilizadas por las élites en sus transacciones internacionales. En el caso de México sus propuestas han sido discutidas con rigor por Antonio Ibarra, ${ }^{26}$ quien a partir de la experiencia de Guadalajara subraya en cambio la importancia de la moneda y del mercado para esa región, a la vez que su discusión sobre la plata y la moneda, como las formas asumidas por la circulación interna del metal es pertinente para una mejor conceptualización de las economías coloniales animadas por los metales preciosos. ${ }^{27}$

Sobre el papel de las monedas acuñadas en Santafé es casi nada lo que se puede decir, por lo menos por el momento. No se sabe, en efecto, cuál fue su destino una vez que salieron de las cecas, como tampoco las diferentes unidades en que fueron acuñadas. Tampoco la historiografía colonial ha analizado con pertinencia los problemas vinculados a la articulación entre economía y moneda, con la excepción notable de Guido Barona ${ }^{28}$ quien a propósito de Popayán sostiene que la articulación funcional entre campo minero y empresa agraria impidió que las minas de esa región jugaran el mismo papel que Potosí en los Andes meridionales.

La segunda interrogante se refiere a los determinantes de la producción minera y de sus ciclos en Mariquita. Ha sido Peter Bakewell ${ }^{29}$ quien formuló de manera muy precisa los determinantes de las diferencias entre la minería de Nueva España y del Perú, y quien también enfatizó el papel crucial de la mano de obra libre en Potosí ${ }^{30}$ y del azogue en México. ${ }^{31}$ En términos generales, los determinantes de esta producción son una función

\footnotetext{
${ }^{26}$ Antonio Ibarra, "Debate. Mercado colonial, plata y moneda en el siglo XVIII novohispano: Comentarios para un diálogo con Ruggiero Romano a propósito de su nuevo libro," Historia mexicana 49, no. 2 (1999): 279-308.

27 Antonio Ibarra, "El Mercado no monetario de plata y la circulación interior de importaciones en la Nueva España. Hipótesis y cuantificación de un modelo regional: Guadalajara, 1802-1803," en Dos décadas de investigación en historia económica comparada en América Latina: Homenaje a Carlos Sempat Assadourian, ed. Margarita Menegus (México, D.F.: Colegio de México, 1999), 445-66.

${ }^{28}$ Guido Barona Becerra, La maldición de Midas en una región del mundo colonial: Popayán, 1730-1830 (Cali: Universidad del Valle, Editorial Facultad de Humanidades, 1995).

${ }^{29}$ Peter J. Bakewell, "Los determinantes de la producción minera en Charcas y en Nueva España durante el siglo XVII," en El sistema colonial en la América Española, ed. Heraclio Bonilla (Barcelona: Crítica, 1991), 58-72.

${ }^{30}$ Peter J. Bakewell, Miners of the Red Mountain: Indian Labor in Potosí, 1545-l650 (Albuquerque: University of New Mexico Press, 1983).

${ }^{31}$ Bakewell, Silver Mining and Society.
} 
de la demanda o de la oferta, contándose en el caso de la primera la coyuntura económica internacional o del entorno, y en el caso de la oferta la riqueza de las vetas, la disponibilidad de insumos importantes como el azogue, el costo del capital y, por cierto, el volumen y la calificación de la mano de obra. En el trabajo de Julián Ruiz sobre Mariquita, al igual que en los juicios de los contemporáneos, el desempeño de la plata de esa región estuvo estrechamente asociado a la mano de obra, particularmente la indígena. Y es ésta la discusión que ahora importa presentar.

\section{Mita y mano de obra}

De la misma manera como la minería neo-granadina dependió fundamentalmente del oro, la fuerza de trabajo ocupada en su extracción fue fundamentalmente proporcionada por los esclavos, particularmente en el siglo XVIII. La excepción, otra vez, fue Mariquita y otros yacimientos que no sólo utilizaron mano de obra nativa, sino que su reclutamiento guardó grandes semejanzas con la mita andina instituida a mediados del siglo XVI por el Virrey Francisco de Toledo. Pero mientras que en Potosí la abrumadora mayoría de los mineros eran indios libres o forzados, en Mariquita, en cambio, la mano de obra indígena representaba aproximadamente el $60 \%$ y el saldo, el $40 \%$, eran esclavos. ${ }^{32}$ Pese a esta combinación, el trabajo de los indios al parecer fue decisivo, al punto de que testigos de la época atribuyen el colapso de Mariquita a la prohibición del Rey en 1720 para que los indios fueran "conducidos" a los yacimientos mineros.

Antes de examinar los mecanismos y las características de la inserción de la mano de obra en las actividades mineras conviene situar esta experiencia en un contexto más amplio. Para Nueva España, Bakewell ${ }^{33}$ señala que el sector minero empleaba a finales del siglo XVI 9,143 trabajadores, de los cuales 1,263 (13.8\%) eran esclavos negros, 6,261 (68.5\%) naborias, es decir trabajadores indios libres, y 1,619 (17.7\%) indios de repartimiento, o trabajadores forzados. En el Potosí de inicios del siglo XVII de los 9,950 trabajadores indios, 4,450 (45\%) eran mitayos y 5,500 (55\%) mingados, es decir voluntarios. ${ }^{34} \mathrm{Ni}$ libres ni forzados eran por cierto trabajadores gratuitos, aunque el jornal diario de ambos era diferente. Los mingas, por su mayor calificación, recibieron diariamente por su trabajo en los socavones 4 reales por día, además de una porción de

\footnotetext{
${ }^{32}$ Ruiz, La plata de Mariquita, 39.

${ }^{33}$ Bakewell, Miners, 182.

${ }^{34}$ Ibid., 127-8.
} 
metal, mientras que el jornal de los indios de mita para un trabajo equivalente era de 3.5 reales.

En uno como en otro caso, el jornal percibido por los trabajadores indios sirvió para el pago de sus obligaciones tributarias, razón por la cual, como fuera anotado por Assadourian, ${ }^{35}$ la renta de la encomienda tendió a monetizarse como una forma adicional de orientar el trabajo de los indios hacia el sector minero. Pero además la historiografía andina ha enfatizado que el tributo pagado era parte de un pacto por el cual los hombres de los Andes aseguraban el acceso a las parcelas de cultivo, razón por la cual estas exacciones fiscales no encontraron una abierta resistencia, a menos que abruptas alteraciones en el pago de los impuestos modificaran desfavorablemente las condiciones de este pacto.

En el caso de la Nueva Granada la situación presenta a la vez semejanzas y agudos contrastes. A diferencia de los Andes centrales y de Mesoamérica, antes de la conquista no existieron organizaciones políticas centralizadas como los Inka o los Azteca, siendo sus diferentes jefaturas étnicas básicamente pre-estatales. Los cálculos de su población, pese a los notables esfuerzos desplegados por Germán Colmenares, ${ }^{36}$ no alcanzan la precisión de los trabajos de Borah y Cook para México o de Cook para el Perú. Sin embargo, las visitas realizadas por la administración colonial, base fundamental de las estimaciones demográficas hasta ahora realizadas, permite también constatar aquí una fuerte disminución de la población indígena. Para la población indígena de Santafé y Tunja, las regiones que suministraron los mitayos indios para Mariquita, el cuadro siguiente elaborado por Ruiz ${ }^{37}$ muestra para el siglo XVII el descenso de la población tributaria:

Tabla 1

Población tributaria de las provincias de Santafé y Tunja durante el siglo XVII

\begin{tabular}{lcccc}
\hline Fecha & Santafé & $\%$ & Tunja & $\%$ \\
\hline $1595-1602$ & 18,070 & 46.95 & 20,416 & 53.04 \\
\hline
\end{tabular}

${ }^{35}$ Carlos Sempat Assadourian, "La producción de la mercancía dinero en la formación del mercado interno colonial: El caso del espacio peruano en el siglo XVI," en Ensayos sobre el desarrollo económico de México y América Latina, ed. Enrique Florescano (México, D.F.: Fondo de Cultura Económica, 1979).

${ }^{36}$ Colmenares, Historia económica y social, 68-108.

${ }^{37}$ Ruiz, Encomienda y mita, 95. 


\begin{tabular}{lrrrr}
\hline $1636-1640$ & 10,178 & 49.39 & 10,429 & 50.61 \\
1690 & 6,924 & 47.15 & 7,758 & 52.84 \\
\hline
\end{tabular}

Como tales, los indios entre los 17 y los 55 años debían pagar diferentes tipos de renta al encomendero, que aquí se denominaba demora, pero también el "requinto," que era un tributo que debían pagar directamente al Rey y que equivalía a la quinta parte de la demora, independientemente de si hacían parte de encomiendas privadas. Se incluían además obligaciones adicionales como el pago de parte del salario del corregidor, el diezmo y el tributo a sus caciques, y cuyos montos variaban de pueblo a pueblo en función de las condiciones específicas de cada uno de ellos. ${ }^{38}$ Estas tasas del siglo XVII reiteraron la proscripción de los servicios personales para el encomendero, e implantaron la libre contratación y alquiler de la mano de obra. Pero en claro contraste con la tendencia a la monetización de la renta de la encomienda, en la Nueva Granada el tributo en especies se mantuvo y muchas veces se prefirió conmutar la renta monetaria por la entrega de mantas. Según la visita de Enríquez analizada por Ruiz, a comienzos del siglo XVII "la gran mayoría de los pueblos de Tunja quedan tasados en mantas, dos mantas de algodón al año, que valoradas a dos pesos allí hacen cuatro pesos de trece quilates de demora. Las tasaciones en oro corresponden casi exclusivamente a los corregimientos de Paipa, Sáchica y Turmequé con una tributación capital de 4 pesos de oro corriente, oro de 13 quilates... Santafé no logra uniformidad de tributos a principios de siglo ni la logrará después. Mientras en una encomienda se cobran 3 pesos de 13 quilates por tributario, más dos gallinas, en otras son 5 pesos mas el par de gallinas. Ya a comienzos de la tercera década empiezan a tasarse los tributos en plata. Mientras en Fosca se exigen dos pesos de plata corriente de 312 maravedís, en Chipaque 1 peso y 4 reales, 1 manta de algodón o 2 de lana y 2 gallinas, y en Ubatoque 3 pesos y 2 reales, más 2 gallinas." ${ }^{\prime 39}$ Pero la escasez de metales preciosos permitió, a espaldas de la ley, que encomenderos y tributarios acordasen el pago de estos tributos en trabajo. ${ }^{40}$

\section{La naturaleza de la "mita" minera en Mariquita}

El ataque contra el servicio personal de los indios fue una de las dimensiones más claras de la Corona en contra de los intereses de los encomenderos, y cuya expresión más

\footnotetext{
${ }^{38}$ Ibid., 225

${ }^{39}$ Ibid., 229.

${ }^{40}$ Ibid., 245.
} 
conocida fue la promulgación de las Leyes Nuevas en 1542. No obstante, como se ha señalado, diversos compromisos se establecieron para asegurar que la mano de obra siguiera siendo utilizada para atender las múltiples necesidades, tanto públicas como privadas, en el Nuevo Reino. Pero aquí interesa discutir una de sus variantes más importantes: el trabajo en las minas.

Una real cédula del 23 de marzo de 1568, permitió a la Audiencia de Nueva Granada autorizar el trabajo de los indios en los centros mineros, a condición de que se tratara de un trabajo voluntario, jornada limitada y jornal justo y que no fueran desplazados a temples distintos a los que pertenecían. ${ }^{41}$ Estas condiciones fueron consignadas en las ordenanzas de 1570 de la Audiencia, a partir de las cuales el trabajo en las minas sería para los indios una ocupación libre y asalariada. Al confiarse a sus respectivos encomenderos el alquiler de estos indios, no es difícil imaginar que esas restricciones eran completamente nominales. En 1588 el presidente de la Audiencia Antonio González encargó al corregidor Bartolomé de Alarcón y al escribano Gaspar Dávila preparar un informe sobre las minas de Mariquita. En el reporte que el presidente de la Audiencia eleva al Consejo de Indias en mayo de 1590 a partir de los resultados de esa inspección, además de señalar el buen estado de esos yacimientos, detalla que los gastos de los mineros incluían la compra del azogue y de la sal, los jornales de los trabajadores indios de doce reales castellanos por semana de seis días de trabajo, pese a los cuales estimaba en 19 reales y 6 maravedís la ganancia diaria de cada propietario. Dada la importancia de Mariquita, el presidente de la audiencia terminaba sugiriendo la necesidad de reclutar unos 1,300 indios, 560 para los ingenios y 740 en los socavones, a la espera de ser reemplazados por unos dos mil negros. ${ }^{42}$ Fueron estas recomendaciones el antecedente de la organización de la mita minera implementada por el presidente Borja en 1612, por la cual el 2\% de la población indígena de Tunja y Santafé debía ser "conducida" a Mariquita.

Mariquita era un pequeño pueblo, en torno a un damero, con 4 cuadras de longitud y 4 de latitud, además de algunas casas en el entorno. Contaba con 200 casas, entre las que estaban las tiendas de la calle real. Hubo igualmente una iglesia parroquial con vicario, cura y beneficiado y 15 clérigos de misa, además de 11 vecinos encomenderos con un total de 95 indios de encomienda. ${ }^{43}$ Pero en el entorno habían 398 indios de los 12,000

\footnotetext{
${ }^{41}$ Eugenio Martínez y María Angeles, Tributo y trabajo del indio en Nueva Granada: de Jimenez de Quesada a Sande (Sevilla: Escuela de Estudios Hispano-americanos, 1977), 520.

${ }_{42}$ Ibid., 524-5.

${ }^{43}$ Ruiz, Encomienda y mita, 115-6.
} 
que existieron en el corregimiento de Mariquita, que incluía las poblaciones de Mariquita, Tocaima, Ibagué, Remedios y San Bartolomé de Honda. ${ }^{44}$ Cuando Borja visita las minas de Mariquita constata "Los cien indios y cincuenta negros que hay en estas minas rinden y sacan mas metal que quinientos indios de Potosí. Aqui se sacan tres pesos de ocho reales por quintal y lo menos uno o dos pesos. ${ }^{~} 45$ En su carta al rey del 10 de julio de 1606, comunica su decisión "que del distrito de las ciudades de Santafé y Tunja, donde hay número de más de treinta mil indios, se saquen de cada pueblo a razón de dos por ciento y se lleven al sitio de estas minas con sus mujeres y familias, donde se pueblen como antes de ahora ha habido otros." ${ }^{46}$ En concordancia con esta decisión ese año se enviaron a Mariquita 660 indios de Tunja, cifra que representaba el 2\% de una población de 30,000 que había en ambas provincias. ${ }^{47}$ Las ordenanzas de 1612 que implementan esta decisión establecen que la duración de la mita era de un año, aunque en la práctica la permanencia se prolongaba de dos y medio a tres años, para una jornada laboral de ocho horas a cambio de un tomín y un grano de oro de trece quilates diario.

Para el último tercio del siglo XVII, entre 1666 y 1703, fueron reclutados como mitayos para las minas 8,621 indios, de los cuales 4,757 provenían de Tunja y 3,864 de Santafé. De este total $1,767(20.4 \%)$ huyeron y $518(6 \%)$ murieron por las condiciones de trabajo. El promedio anual de estos desplazamientos fue de 400 indios por año, ${ }^{48}$ con una caída del $50 \%$ en la última década atribuida al descenso de la población y a las fugas de los indios.

\section{Consideraciones finales}

El papel de los centros mineros en la constitución y la ampliación de un mercado monetario se mide por las emisiones de las cecas, por la circulación del metal como mercancía dinero, y por el volumen del gasto monetario. Lo último tiene que ver con las conducciones de los indios, es decir el equivalente formal a la mita minera de Potosí. Formal porque el volumen de estos trabajadores en Mariquita era aproximadamente una décima parte de quienes trabajaban en Potosí, en un marco de una población nativa mucho menor que la de los Andes centrales, además del hecho de que de su

\footnotetext{
${ }^{44}$ Ruiz, La plata de Mariquita, 9.

${ }^{45}$ Citado por Ruiz, Encomienda y mita, 11.

${ }^{46}$ Ibid., 12.

${ }^{47}$ Ibid., 25.

${ }^{48}$ Ruiz, La plata de Mariquita, 49.
} 
remuneración monetaria, el tomín y el grano de oro, en el caso de que les fuese efectivamente pagado en moneda y además no les fuese arbitrariamente retenido por los propietarios, era incomparablemente menor a las remuneraciones en Potosí. Además, no solamente los jornales eran incomparables en uno y otro caso, sino que de ese jornal el mitayo debía pagar el conjunto de las obligaciones tributarias descritas más arriba, sin que en compensación existiese nada similar a la institución de la korpa, ese "robo" de metal y cuya venta compensaba en Potosí lo que el indio perdía en sus ingresos por el pago del tributo.

Todo esto sin mencionar que la mita en Nueva Granada debió representar una experiencia radicalmente nueva para su población nativa, en la medida que no existían, en contraste otra vez con los Andes, claros precedentes prehispánicos, a la vez que su implementación en el siglo XVII fue establecida al parecer completamente por fuera de la articulación simétrica entre pago del tributo y acceso a las tierras de cultivo. Tunja y Bogotá, los lugares desde dónde los mitayos para Mariquita fueron extraídos, no son muy distantes a las minas y bastaban unos 20 a 25 días para llegar a su destino, y en ese sentido su recorrido era mucho menor que el de sus pares del sur andino. Pero esa ventaja relativa se perdía por los bruscos cambios de clima entre las zonas frías de procedencia y el calor intenso en el entorno de Mariquita y cuya consecuencia fue el rechazo al trabajo por parte de los indios. Nada posibilitaba, por consiguiente, la aparición de trabajadores similares a los mingas de Potosí, o a las naborías de Nueva España.

Las consideraciones anteriores no permiten evaluar de manera precisa el papel de Mariquita en la expansión mercantil de la economía de Nueva Granada, como tampoco en el crecimiento de su producto. En efecto, no todos compartían el entusiasmo del alcalde de minas de las Lajas Andrés Pérez de Pisa, y más bien estaban de acuerdo con el juicio que "si bien la plata mantiene este pequeño reino, también la saca de indios lo acabará." 49

\footnotetext{
${ }^{49}$ Monika Contreras, "El trabajo mitayo en el Nuevo Reino de Granada en las minas de plata en Mariquita en el siglo XVII" (ponencia presentada en el I Encuentro de Estudiantes Latinoamericanos de Historia, Villa de Leyva, 2001).
} 
Tabla 1

Acuñación de plata en la Casa de la Moneda de Santafé, 1627-1700.

\begin{tabular}{|c|c|c|c|c|c|}
\hline Año & Pesos de plata & Maravedíes & Años & Pesos de plata & Maravedíes \\
\hline 1627 & 25,929 & $7,052,688$ & 1664 & 59,965 & $16,310,480$ \\
\hline 1628 & 190,657 & $51,858,704$ & 1665 & 21,030 & $5,720,160$ \\
\hline 1629 & 97,728 & $26,582,016$ & 1666 & 15,234 & $4,143,648$ \\
\hline 1630 & 72,745 & $19,786,640$ & 1667 & 78,792 & $21,431,424$ \\
\hline 1631 & 86,221 & $23,452,112$ & 1668 & 33,106 & $9,004,832$ \\
\hline 1632 & 61,799 & $16,809,328$ & 1669 & 23,483 & $6,387,376$ \\
\hline 1633 & 39,404 & $10,717,888$ & 1670 & 15,927 & $4,332,144$ \\
\hline 1634 & 34,396 & $9,355,712$ & 1671 & 15,935 & $4,334,320$ \\
\hline 1635 & 10,737 & $2,920,464$ & 1672 & 15,927 & $4,332,144$ \\
\hline 1636 & 8,400 & $2,284,800$ & 1673 & 15,936 & $4,334,592$ \\
\hline 1637 & 3,182 & 865,504 & 1674 & 8,442 & $2,296,224$ \\
\hline 1638 & 95,190 & $25,891,680$ & 1675 & 0 & 0 \\
\hline 1639 & 6,448 & $1,753,856$ & 1676 & 0 & 0 \\
\hline 1640 & 8,718 & $2,371,296$ & 1677 & 0 & 0 \\
\hline 1641 & 11,449 & $3,114,128$ & 1678 & 0 & 0 \\
\hline 1642 & 10,251 & $2,788,272$ & 1679 & 0 & 0 \\
\hline 1643 & 31,808 & $8,651,776$ & 1680 & 21,072 & $5,731,584$ \\
\hline 1644 & 0 & 0 & 1681 & 0 & 0 \\
\hline 1645 & 0 & 0 & 1682 & 0 & 0 \\
\hline 1646 & 46,624 & $12,681,728$ & 1683 & 8,626 & $2,346,272$ \\
\hline 1647 & 12,981 & $3,530,832$ & 1684 & 10,016 & $2,724,352$ \\
\hline 1648 & 45,225 & $12,301,200$ & 1685 & 0 & 0 \\
\hline 1649 & 37,009 & $10,066,448$ & 1686 & 0 & 0 \\
\hline 1650 & 14,886 & $4,048,992$ & 1687 & 12,361 & $3,362,192$ \\
\hline 1651 & 67,636 & $18,396,992$ & 1688 & 4,246 & $1,154,912$ \\
\hline 1652 & 31,356 & $8,528,832$ & 1689 & 0 & 0 \\
\hline 1653 & 27,889 & $7,585,808$ & 1690 & 22,721 & $6,180,112$ \\
\hline 1654 & 183,680 & $49,960,960$ & 1691 & 821 & 223,312 \\
\hline 1655 & 63,776 & $17,347,072$ & 1692 & 5,653 & $1,537,616$ \\
\hline 1656 & 17,169 & $4,669,968$ & 1693 & 5,796 & $1,576,512$ \\
\hline 1657 & 31,230 & $8,494,560$ & 1694 & 4,874 & $1,325,728$ \\
\hline
\end{tabular}




\begin{tabular}{lrrrccr}
\hline Año & Pesos de plata & Maravedíes & & Años & Pesos de plata & Maravedíes \\
\cline { 6 - 7 } 1658 & 24,438 & $6,647,136$ & & 1695 & 1,064 & 289,408 \\
1659 & 13,660 & $3,715,520$ & & 1696 & 0 & 0 \\
1660 & 59,965 & $16,310,480$ & & 1697 & 11,424 & $3,107,328$ \\
1661 & 59,965 & $16,310,480$ & & 1698 & 38,165 & $10,380,880$ \\
1662 & 59,965 & $16,310,480$ & & 1699 & 12,588 & $3,423,936$ \\
1663 & 59,965 & $16,310,480$ & & 1700 & 18,760 & $5,102,720$ \\
\hline
\end{tabular}

Fuente: Céspedes del Castillo, Las cecas indianas, 262-8. 